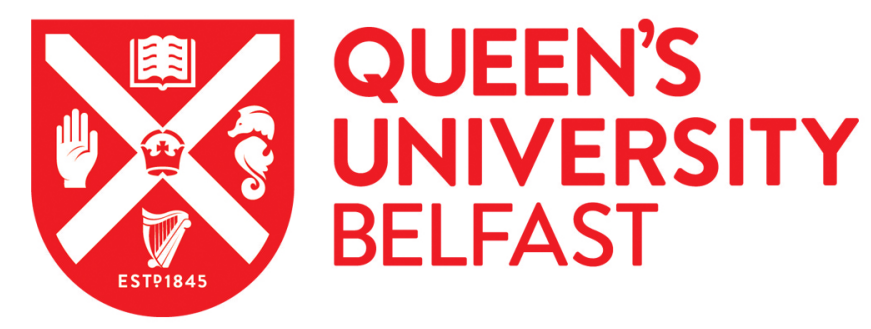

\title{
The development of a web-based resource to provide information and psychosocial support to informal cancer carers in hospital in Vietnam
}

Santin, O., Jenkins, C., Hoa, N., Prue, G., Lohfeld, L., Reid, J., \& Ho Thi, H. (2020). The development of a webbased resource to provide information and psychosocial support to informal cancer carers in hospital in Vietnam. Psycho-oncology, 29(5), 920-926. https://doi.org/10.1002/pon.5368

Published in:

Psycho-oncology

Document Version:

Peer reviewed version

Queen's University Belfast - Research Portal:

Link to publication record in Queen's University Belfast Research Portal

Publisher rights

(c) 2020 John Wiley \& Sons, Ltd

This work is made available online in accordance with the publisher's policies. Please refer to any applicable terms of use of the publisher.

\section{General rights}

Copyright for the publications made accessible via the Queen's University Belfast Research Portal is retained by the author(s) and / or other copyright owners and it is a condition of accessing these publications that users recognise and abide by the legal requirements associated with these rights.

Take down policy

The Research Portal is Queen's institutional repository that provides access to Queen's research output. Every effort has been made to ensure that content in the Research Portal does not infringe any person's rights, or applicable UK laws. If you discover content in the Research Portal that you believe breaches copyright or violates any law, please contact openaccess@qub.ac.uk. 
Title: The development of a web-based resource to provide information and psychosocial support to informal cancer carers in hospitals in Vietnam

Short running title: A web-based support to meet the needs of informal cancer carers in Vietnam

Authors: 1) Olinda Santin 2) Chris Jenkins 3) Hoa Le Phuong Nguyen 4) Gillian Prue 5) Joanne Reid, 6) Lynne Lohfeld, 7) Hien Thi Ho

1) School of Nursing and Midwifery, Queen's University Belfast, Medical Biology Centre, 97 Lisburn Road Belfast

2) Centre for Public Health, Institute of Clinical Sciences, Block B, Royal Victoria Hospital, Belfast

3) National Cancer Hospital Hanoi Vietnam National Cancer Hospital, 30 Cau Buou St., Thanh Tri, Hanoi, Viet Nam

4) School of Nursing and Midwifery, Queen's University Belfast, Medical Biology Centre, 97 Lisburn Road Belfast

5) School of Nursing and Midwifery, Queen's University Belfast, Medical Biology Centre, 97 Lisburn Road Belfast

6) Centre for Public Health, Institute of Clinical Sciences, Block B, Royal Victoria Hospital, Belfast

7) Faculty of Clinical Medicine, Hanoi University of Public Health, 1A Duc Thang St., Bac Tu Liem District, Hanoi, Viet Nam 
Objective: Vietnam, like many low/middle income countries, lacks the infrastructure to provide information and psychosocial support to cancer patients and their carers. We undertook a co-design process to develop a web resource to inform and support carers.

Methods: Cancer carers and health care professionals' perspectives regarding information and support needs and the content and delivery of web-based supports, were explored via 5 focus groups $(n=39)$ and semi-structured interviews $(n=4)$ in Vietnam in 2018. Focus groups and interviews were transcribed verbatim and analysed using thematic analysis. Resource components were verified at two joint stakeholder workshops attended by 40 participants.

Results: The development of a web-based resource was identified as an urgent need. A web-based resource was viewed as a suitable interface to provide support across regions in a sustainable way. The structure of the resource should include peer-led videoed advice, signposting to services and include official endorsement. The potential resource components identified included 1) cancer causes and consequences; 2) hospital administration, treatment processes and prices; 3) daily living; 4) emotional and supportive information; 5) skills training; and 6) nutrition and traditional medicine.

Conclusion: The development of a web-based resource to deliver information and psychosocial supports to cancer carers and by-proxy patients is an urgent requirement in Vietnam. Next steps will include resource development and testing the resources ability to address the unmet needs of cancer carers and patients. A web-based resource to support cancer carers has the potential for application to other developing countries.

Keywords: Cancer, Caregiver, Carer, Informal Care, Intervention, Oncology, Web-based, Resource, Hospitals, Vietnam. 
Vietnam is experiencing a rapid increase in the number of people diagnosed with cancer (1). The number of new cancer cases reported in 2018 was estimated to be 114,871, with 70\% of patients diagnosed at a late or incurable stage $(1,2-4)$. Cancer estimates and death rates have tripled since 1990 , demonstrating the rising burden of cancer in Vietnam $(1,4)$. This rising population places increased and sustained pressure on the limited diagnosis and treatment resources available (1). As the prevalence of cancer rises, so too do the number of people (usually family members), providing informal care. This large population of informal carers is currently without sufficient information and support (1).

Informal cancer carers (ICC) are of particular importance to the delivery of support and care for Vietnamese patients. Vietnamese ICC undertake multiple roles from helping to access health care facilities, making treatment decisions, providing informational and emotional support, and providing medical care. Cancer often causes a financial catastrophe, with up to $70 \%$ of Vietnamese families pushed into significant poverty (5-7). For many people, becoming a carer happens suddenly, with little time to develop the skills to assist them to navigate this role. As hospital infrastructure struggles to meet the demands of diagnosis and treatments, the majority of the care responsibility (including inpatient care) falls on the ICC.

Providing cancer care can have a profound negative impact on the health of ICC, particularly as the patients' health declines (8-11). The cost of providing informal care is burdensome for the individual, leading to increased absenteeism, hospital admissions and health service use (10), as well as poor physical and mental health. As ICC are fundamental to the delivery of cancer services in Vietnam, it is imperative that they are adequately supported. In addition, due to the inter-dependence of patient and ICC health, supporting ICC has the potential to impact upon patient health and wellbeing (12-13).

Support and care in the form of palliative care units are sparse and only exist in Hanoi and Ho Chi Minh City (HCMC) and three other provincial hospitals in Vietnam (2). These units focus exclusively on meeting patients' physical needs (4). Services such as social work, counselling, support and information, which are integral to holistic cancer services in high-income countries, are underdeveloped. At present, palliative and supportive care, responsibility falls on the ICC, with $90 \%$ of patients dying at home being cared for by their families. As a result of rising numbers, limited resources and lack of infrastructure, the information and psychosocial support needs for both patients and their families remain highly prevalent and unmet (14).

Providing an effective intervention for a population currently without sufficient information or psychosocial supports is a policy priority for Vietnam (1). A recent review has found limited empirical evidence for the use of face-to-face supports (15). In response to unmet needs of cancer carers in the UK (11), an online resource was co-designed by ICC for cancer carers (16). The web-based support www.cancercaringcoping.com has been evaluated as an appropriate and cost effective way to support families. There is increasing evidence for the use of online interventions to support cancer carers, particularly due to their wide reaching and sustainable mode of delivery (17). With this in mind, the overall aim of the project is to collaboratively develop a web-based resource to provide information alongside practical and emotional advice and support to ICC in Vietnam. This paper presents the first two stages of this co-design process including the identification of need and the design of the resource content. We propose a co-designed resource may have the potential to inform and support ICC and has potential application in many other LMICs in the future. 


\section{Methods}

This study followed a co-design methodology (16), occurring over 2 phases: Phase 1: the identification of ICC needs and Phase 2: Stakeholder verification.

Phase 1 the identification of ICC needs: involved gathering an in-depth understanding of the needs of ICC to underpin resource content. Focus groups and in-depth interviews were conducted in Hanoi and HCMC oncology hospitals until the point of saturation with the following groups:

I. Health Care Professionals (HCP): Doctors, nurses or allied health professionals in the National Cancer Hospital in Hanoi (K Hospital) and the HCMC Oncology Hospital.

ii. ICC: Informal carers aged 18 years or over who is providing care for a patient with any type or stage of cancer at $\mathrm{K}$ hospital and the HCMC Oncology Hospital.

To recruit HCPs, hospitals were contacted via email, providing details of the study objectives. Hospital representatives circulated an email invite to all medical staff requesting that interested participants email their contact details. HCPs were offered the option of participating in a semi-structured interview or focus groups. ICC were recruited via identified HCP in both hospitals. A combination of purposive and snowball sampling was used; gatekeepers approached ICC currently providing care to a cancer patient receiving inpatient treatment.

Two interview schedules were developed for ICCs and for HCPs; these were based on our previous carer intervention development (16). Interview schedules were adapted and modified by Vietnamese speaking cancer experts and cancer patients via face to face discussions. Focus groups were conducted in Vietnamese by HTH and were attended by OS, CJ and HN. HN provided a partial simultaneous translation for $\mathrm{OS}$ and $\mathrm{CJ}$ to avoid interrupting the flow of the conversations while also providing the non-Vietnamese research team an opportunity to input probes and clarifications.

All interviews and focus groups were audio recorded and transcribed verbatim in Vietnamese and then professionally translated to English for analysis. Thematic analysis (18) was applied to the transcripts. $\mathrm{HTH}$ and HN travelled to the United Kingdom (UK) for a period of ten days to conduct data analysis. Analysis was completed in both Vietnamese and English with teams of researchers analysing and coding transcripts. Pairs of researchers coded identical transcripts until inter-rater reliability was reached.

Phase 2: Stakeholder verification and refinements: ensured respondent validation of the nature of needs identified and the potential components of the web-based resource. A half-day joint co-design workshop was held in each hospital in Hanoi and HCMC. These workshops allowed both ICCs and HCPs to learn of each other's perspectives and to agree upon shared priorities and resource components. All HCPs who previously participated in focus groups or interviews were invited to participate. As 4 months had passed since the original interviews, it was not possible for ICC interviewees to attend as many lived long distances from the hospital. In order to ensure the ICC voice was represented, ICCS currently providing care for cancer inpatients in both hospitals were invited to attend to give their views and opinions on the findings. A large focus group discussion was conducted in Vietnamese, with each participant taking an individual opportunity to provide their feedback on the themes and content identified. Any additional points not identified in earlier workshops were discussed until group consensus was reached. Feedback was detailed by OS/CJ/HH in detailed field notes. 


\section{Results}

In phase 1: 23 professionals participated in either an interview $(n=4)$ or a focus group $(n=19)$, and 20 ICCS participated in focus groups only. Interviews lasted for approximately 45 minutes with the average time for focus group being $1 \mathrm{hr}$ and 15 minutes.

Hanoi K Hospital: 4 in-depth interviews with oncologists and one focus group ( $n=6)$ with 4 nursing staff, a social worker, and a nutritionist from departments of surgery, internal medicine, abdominal surgery, radiology, and social work. Participants included a range of both junior and senior staff.

HCMC Oncology Hospital: Two focus groups were conducted one with 7 junior and senior nurses and one focus group with 6 senior oncologists from departments of surgery, internal medicine, radiology, and palliative care.

ICC: Two focus groups were conducted, one within the National Cancer Hospital in Hanoi ( $n=9)$, and the HCMC Oncology Hospital ( $n=11)$. ICCs were predominately female (65\%), aged between 29 and 72 years, with all carers, (with the exception of one), being direct family members. ICCs provided care for patients with breast, colorectal, oesophageal and ovarian cancer.

In phase 2: 11 ICCs and 29 HCPs participated in stakeholder verification events.

\section{Phase 1 Result}

Results identified three key themes: the mode of delivery of potential information and psychosocial supports, the structure and factors increasing usability of a web-based resource, and the content of a web-based resource.

\section{Mode of delivery of information and psychosocial supports}

The need to develop a web-based resource that provides comprehensive information on managing cancer was highlighted as an urgent issue. A web-based resource was considered a way of providing information and supports to a large population. ICC and HCP reported that an online resource would reduce the burden associated with developing multiple face-to-face or written resources. A webbased resource was viewed as the most accessible option as carers could access the information on their mobile phones or on their computers at a convenient location and time. It was acknowledged that a web-based resource might not meet the needs of all ICCs as some; particularly those who are older or live in rurally. Participants discussed that for these carers there may be merit in providing booklets and leaflets within the hospitals or information displayed on TV screens would be useful.

Although I have tried to take good care of myself, sometimes I cannot do it all. If I had a website focusing on the characteristics of disease, surgery, post-surgery, how to take care of it, how my family members need it, and how to work with the doctor (ICC)

\section{Structure and factors to increase usability of a web-based resource}

Respondents identified that online information should be visual with inclusion of videos and pictures for ease of use; this was viewed as important to meet the needs of all ICCs regardless of level of 
literacy. The development of the online resource should also consider the use of role modelling with the inclusion of successful stories or relay experiences of Vietnamese celebrities. The inclusion of hospital or Ministry of Health endorsement would provide users confidence in the resource and materials. Links to all relevant hospital sites or sites on nutrition or peer support resources was also viewed as important to maximise signposting. The inclusion of a 'Frequently Ask Questions' Section and a search function was suggested as a means to improve usability and allow for information to be targeted. Participants also suggested the inclusion of search filters based on disease type.

Another is if the website can find hospitals that can check for cancer. We can just search and find a series of hospitals can check the hospital (ICC, Hanoi)

\section{Content of the web-based resource}

Participants identified six key areas to be included within the resource (Table 2) : 1) Cancer Causes and Consequences 2) Hospital administration and treatment processes and prices 3) Managing daily living in hospitals 4) Emotional and supportive information 5) Skills training 6) Nutrition and traditional medicine.

1. Cancer causes and treatment: ICCs reported that their own lack of knowledge about cancer made it difficult to support and inform the patient. This lack of ICC knowledge was supported by the HCP account as they reported that often patients and ICCs did not have a basic knowledge of cancer. Respondents reported that a web-based resource should contain education and information, which included a description of potential and available treatments such as chemotherapy, radiotherapy and surgery. ICCs required information regarding prognosis to help with their understanding of how long a patient may be expected to live. Information regarding the potential side effects of treatment and how to discuss and support the management of symptoms was identified as a priority area.

"Even though we are family members, our knowledge about the field of cancer is still very limited. Now I have to take care of nutrition, psychological health, and I am telling you my experience of patient care is very limited" (ICC).

2. Hospital administration and treatment processes and prices: The hospital administration processes and procedures for accessing treatment and support were considered a challenge for ICC. ICC reported that information listing available cancer hospitals, which hospitals are best and their distances from major cities should be made available to assist with the treatment decision making. ICC reported that information regarding the role of the various departments within the hospitals, the treating doctors and their expertise should be made available. Hospital processes and procedures should be detailed on the website that inform carers regarding how to register the patient, how to schedule a check-up as well as the procedure for bringing the carer for examination and treatment.

"This website needs to have information before going to the hospital, it has to provide information, there is a list of this hospital, to calculate the distance to the hospital and if that hospital provides services related to you. This and the basic cost and the most basic examination time so we can have a quick overview before people come" (HCP)

3. Managing daily living in hospitals: Both ICCs and HCPs discussed that commonly when a family member is diagnosed with cancer the ICC will travel long distances and stay with the patient as they receive inpatient treatment. For many ICCs this involves sleeping on the hospital floor or corridors, 
with many experiencing challenges with finding safe accommodation, difficulties finding locations to wash, eat, and do laundry. All respondents described the need for ICCs to receive information on how to take care of their own basic needs whilst a patient was in hospital as an important resource component. ICCs described a need for information on what costs to expect whilst a patient is in hospital, how to manage their associated budget and how to access information on insurance.

"I have to work in the field, but now I have to leave my rice field. The farmer works on some acres of square rice field then leave for hospital to take care of our family member." (ICC)

"The rooms are crowded, they (ICC) do not have a place to lie down, and they lie outside or rent a place outside the hospital" (HCP)

4. Emotional and supportive information and advice on how to cope: HCPs noted that due to the high number of patients requiring their attention that they had limited opportunity to provide information and support to ICC. HCPs and ICCS suggested targeting the resource to the psychological challenges, providing specific advice and support to help ICCs cope with common emotions such as shock, stress and depression. In addition, ICCS discussed that family and relationship conflicts can add to the psychological burden of caring. ICCs requested the resource contained advice on how to assist families and couples to communicate and manage conflict.

"I am very worried when mother has a problem. The day that my mother was here, was the day my mother had surgery, I had my mind prepared for the cremation already. It means that we need to prepare the mind, to prepare who will help me at home solve that problem. That is, the psychological difficulties are so heavy/stressful." (ICC)

5. Skills training including signposting to support and information: ICCs would benefit from interactive skills based training that would assist them to manage issues such as how to give comfort, how to motivate patients and how to talk about cancer or give bad news. They reported that the resource should provide disease tailored information on how to deal with more common medical issues experienced by patients, such as how to manage medications or pain.

"I have asked the doctor very carefully, so when the doctor came, I asked him what the best way to stop bleeding is and how to treat haemorrhage. The doctor also told us some methods, and then it's temporarily stable now. But the thing is when I get home, I don't know how to treat them" (ICC/HCMC)

6. Nutrition and traditional medicine: Participants reported that each component of the web-based resource should contain information on nutrition and traditional medicine. The inclusion of culturallybased information, in particular traditional medicines or the discussion of foods in terms of those that are important to eat at various points of the cancer journey was viewed as a priority.

Verification of contents in Stakeholder's events: We achieved $100 \%$ consensus through presentation and discussion of the identified needs and components. Complete agreement was also reached on the importance of online delivery and including information that was predominantly visual with the inclusion of videos, pictures and interactive training. It was agreed that an online resource is an important first step to reach a large and wide reaching population of ICC. However it was noted that future research should seek to adapt the material so it can be delivered by other means such as face to face to meet the needs of older carers or those who live in remote locations without internet access. 
Identified module themes were agreed upon and further detail on the content on these components was detailed (See table 2).

\section{Discussion}

The project highlights the need to develop information and supportive care to improve outcomes for those affected by cancer in Vietnam. This study provides the initial development of an evidence-base for effective implementation of interventions to support ICCs and by-proxy assist patients in Vietnam. An outline for the structure and content of a web-based resource was co-designed which aims to provide information, training and support to ICCs. ICCS and HCPs acknowledged that the resource should provide interactive information, training, support and links to services that focus on cancer causes and consequences, hospital administration, treatment processes and prices, how to manage daily living in hospitals, emotional and supportive information, skills training and nutrition, and traditional medicine. This content differs from the previously developed UK based resource CCC-UK (16) by highlighting the importance of cancer specific information, nutrition and traditional medicine, and the inclusion of skills training. This finding is reflective of the level of personal and medical care that is provided by the ICCs in Vietnam that is commonly performed by HCPs in developed cancer services.

Differing from western-based carer interventions (15), Vietnamese ICCs focused on the inclusion of information regarding the healing nature of food and herbal medicines. This finding is rooted in Vietnamese culture whereby foods are considered to have different balancing properties ('hot' and 'cold' foods/yin and yang foods) that create harmony in the body and impacts on disease or illness. This finding highlights the importance of co-design to identify the specific needs and cultural adaptions.

There is limited evidence to support the delivery of face-to-face interventions to improve outcomes for ICC (15). This study demonstrates that ICCS and HCPs are supportive of a web-based interventions whilst recognising that this mode of delivery has limitations particularly in terms of accessibility for older ICCs and those that live in very remote locations. Despite these limitations, online delivery has high potential for reach, with approximately 54 million internet users or $70 \%$ of the population in Vietnam (19). An online resource may provide access to support and information to large numbers of people across several locations in a cost-effective way.

To date, support for interventions for ICCs that utilise online technology have relied on a methodologically weak evidence base (17). Intervention development is best served through codevelopment with multiple stakeholders to draw on their experiences and identify improvements to services (20-21).

\section{Study limitations}

This study has a number of limitations. This study focused on gathering the experiences of ICCs and HCPs within a hospital setting, with a population that are typically younger, able to access healthcare and live in urban areas. Data in relation to the educational attainment of ICCs and whether or not they lived in urban or rural locations was not collected. An understanding of the experiences of a diverse population of ICCS at a local or commune level is necessary.

Clinical Implications 
Future research should develop and test the web-based resource in relation to ICCs and patient outcomes. This study includes the collection of data from multiple stakeholders in multiple sites with analysis of data occurring in two languages. This study provides an example of how the challenges of co-design can be overcome even across countries. This approach could feasibly be applied in many other LMICs as a means of addressing the lack of effective supports. It could also potentially be applied to other chronic disease sites.

\section{Conclusions}

The development of a web-based resource to deliver information and psychosocial supports to ICCS and by-proxy patients was identified as an urgent requirement in Vietnam. It is necessary to develop the resource and examine its ability to address the unmet needs of cancer carers and patients.

\section{Acknowledgements}

Funded by Department for the Economy (DfE) - Global Challenge Research Fund (GCRF) Awards. Acknowledgements to Professor Hoang Van Minh, Hanoi University of Public Health; Dr Dang Huy Quoc Thinh, Vice Director of HCMC Oncology Hospital; Dr. Nguyen Tien Quang and Associate Professor Tran Thi Thanh Huong of Hanoi Cancer Hospital; and patients and carers.

\section{Conflict of Interest Statement}

None

\section{Ethics Statement}

Approval by Institutional Review Board of Hanoi University of Public Health in Vietnam. No. 018442/QD-YTCC.

\section{Data Availability}

The data that support the findings of this study are available from the corresponding author, upon reasonable request. 
References

1) Pham T, Bui L, Kim G, Hoang D, Tran T, Hoang M. Cancers in Vietnam-Burden and Control Efforts: A Narrative Scoping Review. Cancer Control. 2019 Jul 17;26(1):1073274819863802.

2) Van Thuan, $T$, Tuan Anh, $P$, Van Tu, D, Thi Thanh Huong, T. Cancer control in Vietnam: where arewe?|Cancer control. Cancel 2016. http://www.cancercontrol.info/cc2016/cancer-control-in-vietnam-where-we-are/. Accessed June 10, 2019.

3) Bray F, Ferlay J, Soerjomataram I, Siegel RL, Torre LA, Jemal A. Global cancer statistics 2018: GLOBOCAN estimates of incidence and mortality worldwide for 36 cancers in 185 countries. CA: a cancer journal for clinicians. 2018 Nov;68(6):394-424.

4) International Agency for Research on Cancer (IARC). Global Cancer Observatory-Vietnam Population fact sheets. http://gco.iarc.fr/today/data/factsheets/populations/704-viet-namfact-sheets.pdf. Accessed September 1, 2019.

5) Hoang VM, Pham CP, Vu QM, Ngo TT, Tran DH, Bui D, Pham XD, Tran DK, Mai TK. Household financial burden and poverty impacts of cancer treatment in Vietnam. BioMed research international. 2017;2017

6) Sullivan R, Alatise OI, Anderson BO, Audisio R, Autier P, Aggarwal A, Balch C, Brennan MF, Dare $A, D$ 'Cruz A, Eggermont AM. Global cancer surgery: delivering safe, affordable, and timely cancer surgery. The lancet oncology. 2015 Sep 1;16(11):1193-224

7) ACTION Study Group. Financial catastrophe, treatment discontinuation and death associated with surgically operable cancer in South-East Asia: Results from the ACTION Study. Surgery. 2015 Jun 1; 157(6):971-82.

8) Stenberg $U$, Ruland $C M$, Miaskowski $C$. Review of the literature on the effects of caring for a patient with cancer. Psycho-oncology. 2010 Oct;19(10):1013-25.

9) Girgis A, Lambert S, Johnson C, Waller A, Currow D. Physical, psychosocial, relationship, and economic burden of caring for people with cancer: a review. Journal of Oncology Practice. 2012 Dec 4;9(4):197-202.

10) Goren A, Gilloteau I, Lees M, daCosta DiBonaventura M. Quantifying the burden of informal caregiving for patients with cancer in Europe. Supportive Care in Cancer. 2014 Jun 1;22(6):1637-46.

11) Santin O, Treanor C, Mills M, Donnelly M. The health status and health service needs of primary caregivers of cancer survivors: a mixed methods approach. European journal of cancer care. 2014 May;23(3):333-9.

12) Hodges $L$, Humphris GM, Macfarlane G. A meta-analytic investigation of the relationship between the psychological distress of cancer patients and their carers. Social science \& medicine. 2005 Jan 1; 60(1):1-2.

13) Bevans M, Sternberg EM. Caregiving burden, stress, and health effects among family caregivers of adult cancer patients. Jama. 2012 Jan 25; 307(4):398-403.

14) Pham, N., Hoang, L. T., Oanh, N. K., Liem, N. K., \& Van Minh, H. (2019, July 11). Demands and Factors Associated to Psychosocial Support of Cancer Patients at Vietnam National Cancer Hospital. Asian Social Work Journal, 4(3), 35 - 46.

15) Treanor, C. Santin, O. Prue, G. Coleman, H. Cardwell, C. O'Halloran, P. Donnelly, M. (2019) Psychosocial interventions for informal caregivers of people living with cancer. Cochrane Database of Systematic Reviews. 
16) Santin O, McShane T, Hudson P, Prue G. Using a six-step co-design model to develop and test a peer-led web-based resource (PLWR) to support informal carers of cancer patients. PsychoOncology. 2019 Mar; 28(3):518-24.

17) Ploeg J, Markle-Reid M, Valaitis R, McAiney C, Duggleby W, Bartholomew A, Sherifali D. Webbased interventions to improve mental health, general caregiving outcomes, and general health for informal caregivers of adults with chronic conditions living in the community: rapid evidence review. Journal of medical Internet research. 2017;19(7).

18) Miles, M. B., \& Huberman, A. M. (1994). Qualitative data analysis: An expanded sourcebook (2nd ed.). Thousand Oaks, CA, US: Sage Publications, Inc.

19) https://www.statista.com/statistics/369732/internet-users-vietnam/

20) O'Brien, N, Heaven, B, Teal, G, et al. Integrating evidence from systematic reviews, qualitative research, and expert knowledge using co-design techniques to develop a web-based intervention for people in the retirement transition. J Med Internet Res. 2016 Aug; 18(8): e210.

21) Oliver SR, Rees RW, Clarke-Jones L, Milne R, Oakley AR, Gabbay J, Stein K, Buchanan P, Gyte G. A multidimensional conceptual framework for analysing public involvement in health services research. Health Expectations. 2008 Mar;11(1):72-84. 
Table 1: Breakdown of participants

\begin{tabular}{|l|c|c|}
\hline & $\begin{array}{l}\text { Descriptive } \\
\text { Qualitative Study } \\
\text { (Phase 2) }\end{array}$ & $\begin{array}{l}\text { Dissemination } \\
\text { and verification } \\
\text { interviews } \\
\text { (Phase 3) }\end{array}$ \\
\hline Carers & 20 & 11 \\
\hline Doctors & 11 & 12 \\
\hline Other Healthcare Professionals & 11 & 16 \\
\hline Non-government organisations & 1 & 0 \\
\hline Total & $\mathbf{4 3}$ & $\mathbf{4 0}$ \\
\hline
\end{tabular}


Table 2: Co-designed structure and content of web-based resource

\begin{tabular}{|c|c|}
\hline Module & Content \\
\hline Cancer Causes and Consequences & $\begin{array}{l}\text { Cancer definition? } \\
\text { Types of cancer } \\
\text { Prognosis, survival rates of cancer? } \\
\text { Treatment choices/what they involve? } \\
\text { Managing side effects }\end{array}$ \\
\hline $\begin{array}{l}\text { Hospital administration and treatment } \\
\text { processes and prices }\end{array}$ & $\begin{array}{l}\text { List of cancer hospitals } \\
\text { Distances of hospitals from cities } \\
\text { Prices of examination/ treatment } \\
\text { Details of treating doctors } \\
\text { Procedure of registration examination and treatment } \\
\text { Various hospital departments }\end{array}$ \\
\hline Managing daily living in hospitals & $\begin{array}{l}\text { Accomodation costs } \\
\text { Where is safe to stay } \\
\text { Laundry } \\
\text { Water } \\
\text { Cooking } \\
\text { Finances } \\
\text { How to balance employment } \\
\text { Information on insurance. }\end{array}$ \\
\hline Emotional and Supportive needs & $\begin{array}{l}\text { Emotional and communication needs: } \\
\text { Shock and acceptance of diagnosis } \\
\text { Dealing with emotions, stress and depression } \\
\text { Stresses on relationships } \\
\text { Current Support Available }\end{array}$ \\
\hline Skills training & $\begin{array}{l}\text { Medications and pain relief } \\
\text { Supporting treatment } \\
\text { Supporting nutritional needs } \\
\text { Managing family conflict } \\
\text { How to give comfort } \\
\text { How to motivate patients } \\
\text { How to share bad news } \\
\text { How to talk about end stages of cancer }\end{array}$ \\
\hline Nutrition and traditional medicine & $\begin{array}{l}\text { Relationship with nutrition (what to eat during stages of treatment) } \\
\text { Information about Traditional medicine }\end{array}$ \\
\hline
\end{tabular}

